\title{
High current denshty hollow cathode electron beam source
}

\author{
J. J. Pocca, 8. Szapiro, and T. Verney \\ Electrical Engineering Department. Coioradu State University, Eort Collins, Colorado 80523
}

(Received 23 January 1987; accepted for publication 16 March 1987)

\begin{abstract}
An eleciron beam with current density greater than $30 \mathrm{~A} / \mathrm{cm}^{2}$ and total current of $92 \mathrm{~A}$ has been generated in $5 \mu$ pulses by accelerating the electrons from a glow discharge in a narrow gap betweer two grids. The ratio of the extracted electron beam current to discharge current is approximately 1 . The gun also operates in a do mode.
\end{abstract}

Plasma cathodes that io not suffer diocie closure (collapse of the anoce-cathode gap) are of particular interest in the generation of high current density electron bcam pulses with duration $>1 \mu \mathrm{k}$. Glow discharges have been previousily used to produce electron beams at current densities $<2$ $\mathrm{A} / \mathrm{cm}^{2}:-{ }^{-1}$ Humpries et al, obtained electron bearn current censities up $1015 \mathrm{~A} / \mathrm{cm}^{2}$ at energies $<300 \mathrm{cV}$ from a spark generated, grid controlied plasma catiode. ${ }^{5}$ Recently, an e'ectron beam current of $30 \mathrm{~A}\left(60 \mathrm{~A} / \mathrm{cm}^{2}\right)$ was reported from a grid-stabilized plasma emitter."

Here we report the generation of a high current density $\left(>32 \mathrm{~A} / \mathrm{cm}^{2}\right.$ ) electron beam with a total current of $92 \mathrm{~A}$ by accelerating the clectrons of a hollow cathode glow discharge in the narrow gap between two grids at energies up to $2 \mathrm{keV}$. The current of energetc bean electrons was measured at $15 \mathrm{~cm}$ from the acceleration grid, and does not in. clude the electrons accelerated in the gap, but intercepted by the $40 \%$ opacue acceleration grid. The electron curtent density emitted by the plasma source is larger and approaches $45 \mathrm{~A} / \mathrm{cm}^{2}$.

Our experimental setup is schematically illustrated in Fig. 1. The plasma source is a 5-criam stainless-steel hol-

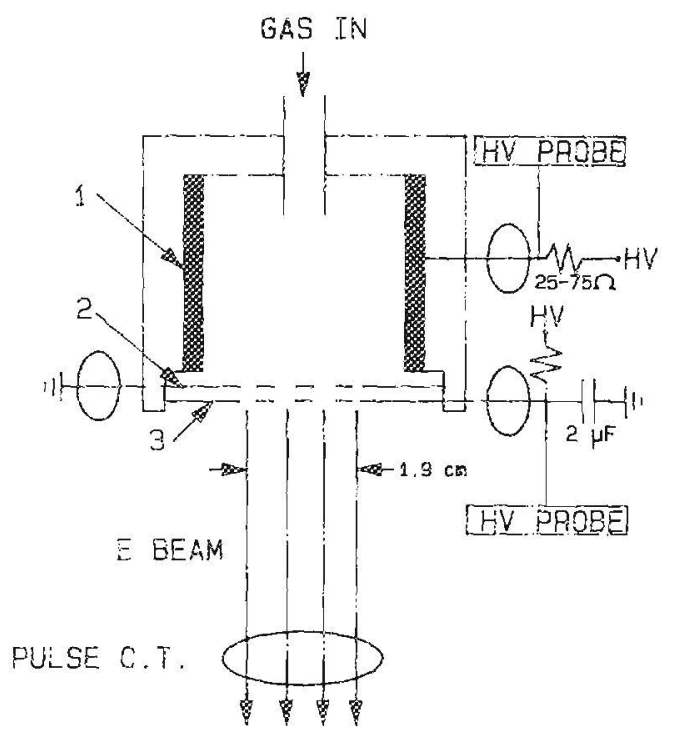

MIG. 1. Experimental setup. The wauum chamber is not shown. The circles represent pulse current transformers. (1) The $5 \mathrm{~cm}$ i.d. hollow cathude, (2) the anode eicctrode, and (3) the acceleration electrode are indicated. The 25-75 2 discharge ballast resistor was only used in the high current experiments, in series with a 50 -nir capacitor.

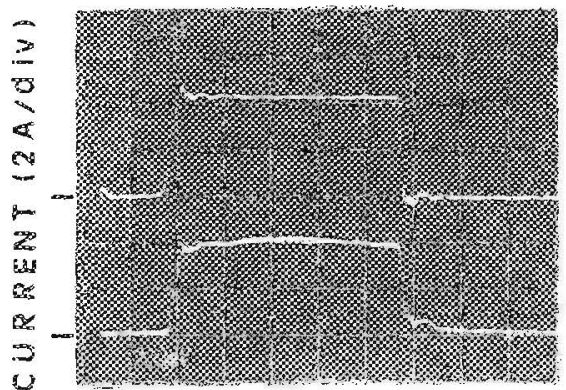

(a)

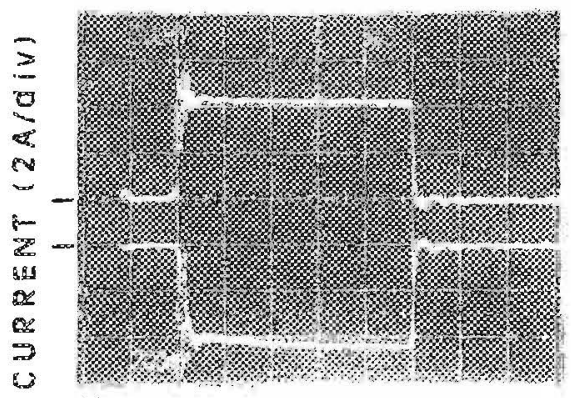

(c)

TI

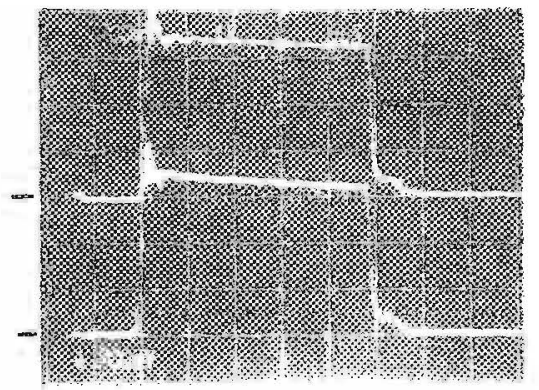

(b)

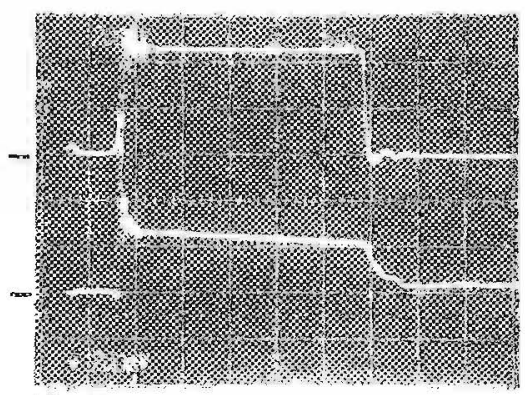

(d)
FIG. 2. (a) Upper trace: discharge current; lower trace: electron beam curront. Accelsration voltage $V_{\text {aciel }}=2 \mathrm{kV}$. (b) Upper trace: surn of discharge and anode gric eurents; fower trace: sum of electron beam and acceleration grid currents. (c) Upper trace: discharge curreni; bottom trace: anode grid current for $V_{\text {axcel }}$ - $0 \mathrm{kV}$. (d) Upper trace: discharge current; tower trace: anote grid current for $V_{\text {wecel }}=2$ $k V$. All vertical scales are $2 \mathrm{~A} / \mathrm{div}$, with the zero fercl indicated in the left margin. The helium pressure was 0.45 Torr. 


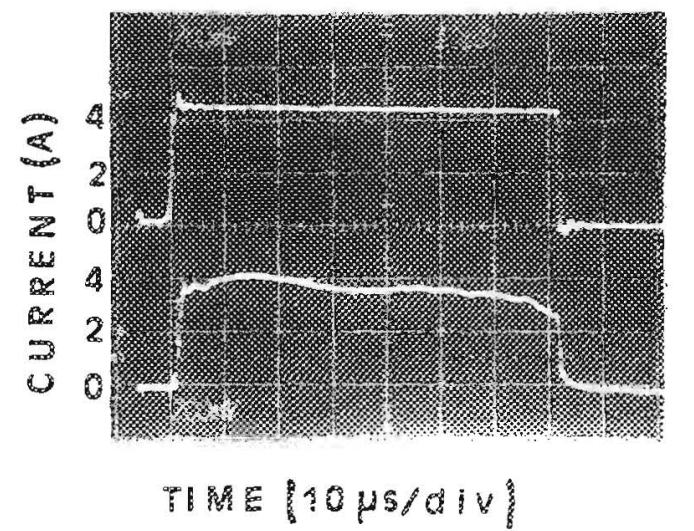

FG. 3. Upper trace: discharge current; lower trace: electron beam current. $V_{\text {wis: }}=2 \mathrm{kV}$. The background helium pressure was 0.45 Tor . The sight current decrease at the end of the electron beam pulse is a consequence of the decrease in the accelerating voluge dec to the charge lost by the biusing cupacitor. Since the bearn current is measured at $15 \mathrm{~cm}$ from the gun, a reduction in accelerating voltage results in increasing scattering leading to the slight current reduction.

low cathode discharge that was operated in helium. Emission is confined to the inner wails of the cylindrical cathode by a Tefon embodment that surrounds the cathode. The Tetion piece also supports two grids that form the 2.5 -mmwide electron acceleration gap. Woib the internal anode grid and the acceieration grid are made of number 42 stainlesssteel mesh, having a transmissivity of approximately $60 \%$. The grids are mounted in supporting stainless-stee? plates having an orifice $19 \mathrm{~mm}$ in diameter that defines the diameter of the extracted beam. The entire electron gur structure was enclosed in a yacuurn chamber and evacuated to a pressure of $10^{-3}$ Torr. Helium was continuously introduced inside the electron gun and evacuated through the grids by a rotatory pump connected to the vacuum chamber. The helium flow caused the pressure inside the electron gun structure to be approximately 1.2 times higher than that in the electron beam drift region of the vacuum chamber. The electron gun was operated at vacuum chamber pressures between 0.1 and 1 Torr. The hollow cathode discharge was excited with a pulse forming network and a high voltage pulsed transformer giving negative voltages up to $6 \mathrm{kV}$. The maximum current this source can provide is $7 \mathrm{~A}$. In experiments at larger currents the hollow cathode discharge was initiated and maintained by discharging a 50-nF capacitor negatively charged up to $8 \mathrm{kV}$ through a series spark gap. h the later case a ballast resistor $(25-75 \Omega)$ was connected in series with the discharge circuit. The anode grid was grounded and the acceleration grid was directly connected to a $2-\mu$ F capasitor charked to provide the desired electron beam energy $(0-2 \mathrm{keV})$. No limiting resistor was added in series with the accelcration grid circuit. The cathode current and the grid currents were monitored with current transformers. The electron beam current was measured by monitoring the current flowing through another current transformer placed coaxial with the beam at $15 \mathrm{~cm}$ from the extraction grid. The voltage drop across the glow discharge and the acceleration gap were also simultaneously measured using commercially availabie high volkage dividers.

The ratio of the electron beam current to the discharge current is close to $\xi$ as shown in Fig. 2(a). The sum of the electron beam current and extraction grid current was observed to be as high as 1.4 times the cathode current. The sum of the former two was measured to exactly match the sum of the discharge current and anode current [Fig. 2(b)]. When no acceleration voltage is applied a negligibie current is collected by the acceleration grid, and the pulse of electron current collected by the anode grid is a good reproduction of

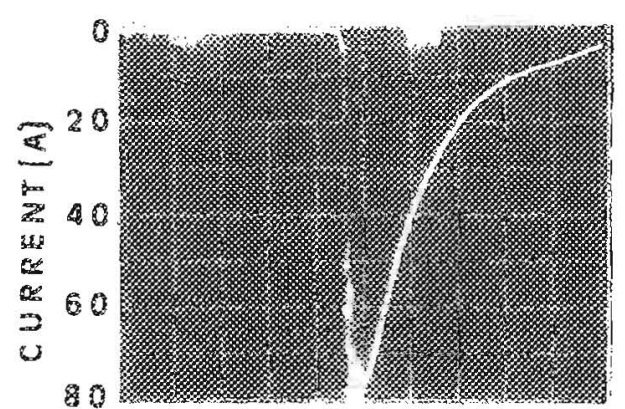

(a)

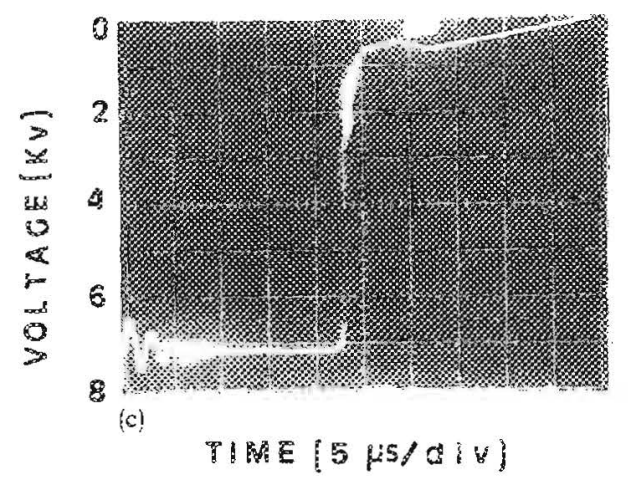

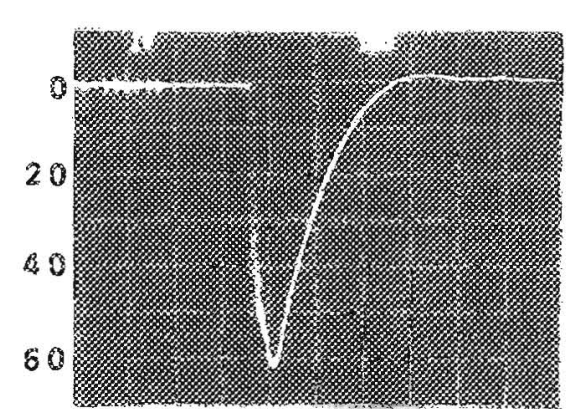

(b)

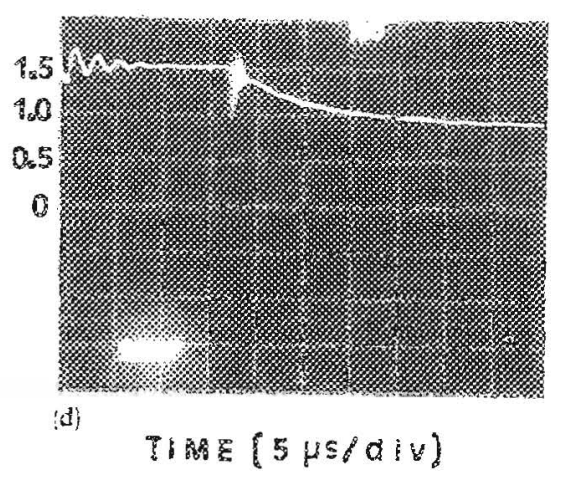

DIG. 4. (a) Discharge curzent. (b) Electron beam current. (c) Lischarge voltage. (d) Acceleration voltage. The background helium pressure was 0.2 Torr. A 75-5/ ballast resistor was used in series with the hollow' cathode discharge current. 
the cathode current puise [Fig, 2(c)] However, when an acceleration voltage greater than $60 \mathrm{~V}$ is applied across the gap, the anode current reverses sign and becomes an ion current as shown in Fig. 2(d). This behavior corresponds to that of grid-controlled plasma cathodes in which the wire spacing in the grids is larger than the width of the spacecharge layer ncar the anode, and is consistent with the theory of Zharinov et al. ${ }^{7}$

The discharge current was observed to be practically unperturbed by the application of an acceleration voltage and the resulting electron beam extraction. Consequently, the electron beam current and energy can be controlled independently. Closure of the acceleration gap does not occur and long electron beam pulses can be obtained. Figure 3 shows a 70 $\mu$ s discharge puise and the corresponding $2-\mathrm{keV}$ electron beam pulse. The gun was also operated in a de mode at electron beam currents of $50 \mathrm{~mA}$.

Figures $4(a)$ and $4(b)$ show a $75-A$ discharge palse and a $62-\mathrm{A}\left(20 \mathrm{~A} / \mathrm{cm}^{2}\right)$ electron beam pulse obtained charging the discharge capacitor to $7.2 \mathrm{kV}$. The voltage drop across the hollow cathode discharge is approximately $600 \mathrm{~V}$, as shown by Fig. $4(c)$. The potential of the acceleration grid [Fig. 4(d)] is observed to decrease smoothly from 1.5 to 1 $\mathrm{kV}$ during the electron beam pulse due to the charge lost by the biasing capacitor. Electron beam current pulses as high as $92 \mathrm{~A}\left(32 \mathrm{~A} / \mathrm{cm}^{2}\right)$ were obtained operating the gun at a background helium pressure of 0.2 Torr and an applied cathode voltage of $8 \mathrm{kV}$.
In conclusion, we have demonstrated the operation of $a$ simple plasma gun at current densities $>30 \mathrm{~A} / \mathrm{cm}^{2}$ in $5 \mu \mathrm{s}$ puises. The beam current was source limited and even larger beam currents should be possible. The gun does not present diode closure and was also operated at reduced currents in the dic mode.

This work is supported by the U.S. Air Force and a C.S. U. Graduate School grant. J. Rocca wants to acknowledge the support of a National Science Foundation Yresidential Young Investigator Award and B. Szapiro the support from the Universidad Nacional de Buenos Aires for his fellowship.

'S. Inumpries, st, S. Coffey, M. Savage, L. K. Len, G. W. Cooper, and D. M. Wondall, J. Appl. Phys. 57, 709 (1985).

2ڤ. Wernsman, H. Ranea Sandoval, J. J. Rocca, and H. Mancini, IEEE Trans. Plasria Sci. RS-14, 518 (1986).

${ }^{3}$ T. Fusayama, Jpn. J. Appl. Phys. 25, L406 (1986).

4. R. Bayless and R. C. Knechtli, [EEE. Q. Quantum Flectron. QE-30, 213 (1974).

${ }^{5}$ S. Humpries, Jr., N. Savage, and D. M. Wcodall, Appl. Phys. Lett. 47,468 (1985).

'A. V. Zharinov, Yı. A. Koyalenko, I. S. Roganov, and P. M. Tyuryukanov, Sov, Phys. Tech. Phys. 31, 39 (1986).

'A. V. Zharinov, Yu. A. Kovalenko, S. S. Roganov, and P. M. Tyuryukanov, Sov. Phys. Tech. Phys. 31, 413 (1986). 